\title{
Europa antes de Europa. Ficciones y realidad de la comunidad supranacional
}

europea. Siglos XVIII-XX

Mikel Martínez Roda ${ }^{1}$ mikelmroda@gmail.com
Europe before Europe. Fictions and reality of the supranational European community. XVIII-XX centuries

\section{Resumen}

Desde la teorización intelectual ilustrada en los siglos XVII y XVIII, la idea de Europa ha asumido el significado de una civilización europea singular y diferenciada, noción vinculada a proyectos de paz continental que tuvo que afrontar la crisis de civilización vivida en el embate de dos Palabras clave: Europa, identidad europea, civilización europea, construcción europea, Unión Europea.

\section{Abstract}

From the illustrated intelectual theorization in the seventeenth and eighteenth centuries, the idea of Europe has assumed the meaning of a singular and differentiated European civilization, a notion linked to projects of continental peace that had to face the civilizational crisis Key words: Europe, European identity, European civilization, European construction, European Union.

1 Universidad del País Vasco, Departamento de Historia Contemporánea, España Instituto Universitario de Historia Social Valentín de Foronda, Edificio Las Nieves, calle Nieves Cano 33, 01006 Vitoria-Gasteiz, Álava, España. guerras mundiales. En el presente artículo se analiza la narrativa dominante de la idea de Europa como discurso de poder en la contemporaneidad y su concreción en la primera construcción comunitaria iniciada con la Declaración Schuman el 9 de abril de 1950. with the outbreak of two world wars. This paper analyzes the dominant narrative of the idea of Europe as a discourse of power in the contemporary era and its concretion into the first European construction initiated with the Schuman Declaration on April 9, 1950. 


\section{Introducción}

"La Unión Europea sufre una crisis existencial", afirmó el presidente de la Comisión Europea Jean-Claude Juncker en el discurso sobre el estado de la Unión ante el parlamento comunitario el 13 de septiembre de 2017. ${ }^{2}$ La implosión de la Gran Recesión en 2008 ha dejado en evidencia la crisis estructural del sistema económico mundial, proceso que ha afectado de forma severa los cimientos del edificio europeo. La crónica de esta crisis es conocida: creciente asimetría entre países acreedores y deudores, aplicación de la ortodoxia de la austeridad, rescates bancarios, endeudamiento de los países periféricos, desempleo masivo, pulso griego a los mandatos económicos de Bruselas, crisis migratoria en el Mediterráneo, decisión del electorado británico de abandonar la Unión Europea, ascenso de partidos populistas de uno y otro signo en Europa y victoria de Donald Trump en las elecciones presidenciales estadounidenses. La construcción europea ha visto así interrumpida la lógica que históricamente ha acompañado a su integración. El relato de la inevitable integración y ampliación ha sido cuestionado, afrontando por primera vez la propia desintegración y aflorando los descontentos sobre la razón de ser del proyecto comunitario. Las palabras de Juncker sintetizaban la situación con claridad meridiana: la Unión Europea se halla en un punto de inflexión sin precedentes ante la crisis hace tiempo advertida de su propio relato (Moreno Juste, 2013, pp. 607-630).

Las tribulaciones del presente llevan implícito un cuestionamiento de la idea representada por la Unión Europea: ¿qué es la Unión Europea?, ¿representa a Europa?, ¿qué es Europa?, ¿qué significa ser europeo? El escritor Milan Kundera (1987, p. 142) lo resumió así: "Europeo: el que siente nostalgia de Europa". Los tiempos de melancolía invitan a la ensoñación. Determinar qué es Europa, en qué momento nace Europa, implica cierto artificio, cierta narración del pasado al servicio de los designios del presente; entre quienes ven en la construcción europea iniciada en 1950 el momento inaugural de Europa y quienes lo retrotraen a los albores de la Grecia clásica median más de dos mil años de historia que, desde la Antigüedad a la Ilustración pasando por la Edad Media o el romanticismo, bien pueden servir para justificar una visión de lo que Europa es o debería ser. Toda coyuntura de crisis, en suma, abre el espacio a la metafísica para paliar los males del presente.

$2 \mid \begin{aligned} & \text { "Juncker: La Unión Europea sufre una crisis existencial, pero no se va a romper". Eu- } \\ & \text { ronews, } 14 \text { de septiembre de 2017. Rescatado de: http://es.euronews.com/2016/09/14/ } \\ & \text { juncker-la-union-europea-sufre-una-crisis-existencial-pero-no-se-va-a-romper }\end{aligned}$ 
No es la reflexión ontológica de Europa lo que nos concierne a los historiadores. El análisis riguroso del pasado debe servir para anclar en el tiempo la idea de Europa que ha terminado tomando cuerpo en el primer germen de la construcción europea. Así, el presente estudio parte de la premisa teórica de que toda idea de Europa es una definición contingente, esto es, es el producto del encuentro entre diversas tradiciones de pensamiento en un contexto histórico preciso. Entendemos así, con B. Stråth (2002), que la idea de Europa es fundamentalmente la historia de un concepto y un discurso, cuyo análisis precisa dilucidar los antecedentes históricos que han vertebrado los diversos significados del significante Europa.

De este modo, se parte aquí del hecho de que Europa, en el momento en el que se identifica con un cuerpo institucional de índole supranacional, esto es, a partir de la declaración Schuman del 9 de abril de 1950 y del Tratado de París del año siguiente, es un constructo institucional y político generado en un contexto histórico preciso. Se infiere, por tanto, que para que Europa se concretara políticamente debió hacerse posible históricamente, en virtud de unas circunstancias que explican la definición identitaria de la Europa naciente. La tarea que proponemos desarrollar en las siguientes páginas consiste en comprender históricamente la idea de Europa, siguiendo el curso sinuoso de su formulación contemporánea y advirtiendo cómo se ha encarnado en las instituciones comunitarias. Todo ello requiere considerar que la identidad no es un discurso autoevidente, sino que se construye en un marco de relaciones de poder determinado. Iniciamos así el análisis de las Europas esbozadas, las Europas posibles y la Europa realmente existente, con el fin último de comprender la confección del relato que ha entrado en crisis en la coyuntura presente.

\section{La educación sentimental.}

\section{Europa imaginada como escenario de paz}

La idea de Europa como comunidad política y cultural es un sentimiento racionalizado por las plumas ilustradas. Este hecho no indica que antes del siglo XVIII no se hablara de Europa con distintas acepciones -fundamentalmente entendida como cristiandad en el Medievo-, pero Europa entendida como escenario de cohabitación de naciones europeas que se perciben integradas en un mismo espacio político, esto es, como concierto europeo, es un producto de los cambios estructurales que se producen en la era de las revoluciones que inauguran la contemporaneidad. Para que una idea concreta de Europa perdure es preciso una identificación, en este caso, una voluntad expresa de apropiarse del contenido que se 
asocia a Europa. Como sostiene Anthony Pagden (2002, pp. 39-40), la idea de identidad significa, hasta bien entrado el siglo XIX, adscripción a comunidades pequeñas: la parroquia, la aldea, el gremio, a veces la región, en el sentido dado a la Heimat germana o a la patria chica castellana, raramente la nación y nunca entidades abstractas como Europa. La identificación supranacional con Europa exigía, por tanto, una operación intelectual que permitiera sentimentalizar un espacio de cohabitación más amplio, el europeo, ejercicio acometido entre las elites letradas de las naciones europeas. Es, en suma, a partir de la segunda mitad del siglo XVIII cuando se dan las condiciones necesarias para imaginar Europa en el sentido contemporáneo.

Europa como comunidad imaginada, por usar la expresión de Benedict Anderson (1993) para referirse a la nación, esto es, como imagen y representación abstracta compartida entre extraños en una lógica horizontal, limitada y soberana, nace con la eclosión de los Estados-nación que derrumban el Antiguo Régimen y prefiguran el mundo contemporáneo, lo que hace de ella un producto moderno y, se puede decir, una teorización intelectual y elitista (Pagden, 2002, pp. 39-40). Es entonces dentro del marco de poder establecido en la paz de Westfalia de 1648 cuando se articula el discurso que apela a una conciencia común compartida por una civilización europea, identificada, en términos políticos, con una República o un Estado y, en lo cultural, con unas creencias, unas leyes y unos modales compartidos. Rousseau, Montesquieu o Robertson, entre otros, teorizan sobre la idiosincrasia continental que encuentra su anclaje en un hecho diferencial: el singular equilibrio de poder europeo emana de una geografía irregular y diversa que predispone a los modernos Estados absolutistas a la competencia y, se deriva, al ejercicio de su libertad. A diferencia del mundo asiático, regido por el dominio de un poder uniforme, monolítico y despótico, Europa es lugar de constante confrontación que posibilita la realización de la libertad. El cartesiano hombre europeo descubre y cataloga el mundo, lo civiliza, lo tamiza sobre las nociones de progreso y atraso (Fontana, 1994, pp. 120-134). Esta Europa ilustrada, esta República de las letras de carácter ecuménico, se articula como concierto europeo garante de un orden mundial, lo que lleva aparejada una afirmación de su supremacía cultural sobre los otros mundos no europeos (Anderson, 2012, p. 487).

Varias son las voces que defendieron la necesidad de una unión continental de Europa en los siglos XVII y XVIII; desde el abate Saint-Pierre a Leibniz, Rousseau o Kant en su célebre Sobre la paz perpetua (1795), todos ellos concibieron la posibilidad de dar con una estructura jurídica supranacional que garantizase la paz continental. Pero si bien a partir de 
la Revolución francesa los Estados nacionales europeos se iban a legitimar sobre la soberanía de un pueblo dotado de una identidad nacional que se construía, afirmaba y reproducía, también la idea de Europa como comunidad requería una traducción al lenguaje contemporáneo de las naciones y la revolución. Una de las primeras figuras que acometió la reformulación del tablero europeo en términos post-absolutistas fue el conde de Saint-Simon (1760-1825), que junto a Augustin Thierry propuso en su Reorganización de la sociedad europea, publicada en 1823, una federación entre estados europeos para asegurar el progreso material y social del continente. Conviene detenerse aquí para ponderar la influencia que ejerce Saint-Simon en la elaboración de la Europa imaginada.

Perry Anderson (2012, pp. 483-511) ha identificado en el pensador francés la figura clave para comprender la reformulación de Europa del contexto absolutista al contemporáneo, impronta de la que derivan tres tradiciones fundamentales para trazar la genealogía del europeísmo en los siglos XIX y XX: a saber, la corriente revolucionaria, la tecnocrática y la conservadora. En primer lugar, la corriente federalista o revolucionaria, que desde Considerant, Mazzini o Cattaneo, pasando por Proudhon, Bakunin, hasta llegar a la izquierda revolucionaria de la primera mitad del siglo xx, desde los bolcheviques rusos, la Tercera Internacional hasta el Manifesto di Ventotene de 1941, evoca Europa como liberación del sometimiento de los Estados nacionales y de su corolario, la guerra. En segunda instancia, aparece una tradición moderada y tecnocrática que hace hincapié en el andamiaje institucional político y económico necesario para construir Europa y que encuentra su momento álgido en torno a la experiencia de la guerra francoprusiana y la experiencia de la Comuna de París entre 1870 y 1871, que tendrá entre sus valedores a figuras de la talla de Víctor Hugo, Giuseppe Garibaldi, Charles Lemonnier, el jurista Johann Kaspar Bluntschli o el conde Richard Coudenhove-Kalergi, entre otros. Por último, destaca la tradición conservadora, que toma del romanticismo la idealización del pasado medieval europeo como un mundo orgánico cimentado sobre un cristianismo armónico y diseña la Europa de la Restauración a partir del Congreso de Viena de 1815 sobre las bases del concierto europeo, esto es, sobre un equilibrio político mantenido a través del principio de injerencia en los países que pudieran desviarse hacia una tendencia liberal, una corriente que en su nómina incluye personalidades como Novalis, Friedrich Schlegel, François Guizot, Friedrich von Gentz, o el historiador Leopold von Ranke. En suma, el esquema ofrecido por P. Anderson identifica en el pensamiento saintsimoniano los motivos que cada una de las tres tradiciones desarrollará en el futuro y, por tanto, permite rastrear la estela del europeísmo posterior. Retomaremos 
al final de este estudio este esquema para identificar la ideación recogida en la primera construcción europea de 1950.

Los llamamientos a la unidad europea serán, pues, múltiples y dispares desde las revoluciones anti-absolutistas que siembran en Europa la semilla del liberalismo y del nacionalismo, lo que plantea el enfrentamiento entre distintas y antagónicas formas de concebir Europa en la encrucijada entre tradición y modernidad. Se entiende, por tanto, que a su entrada en el siglo XIX, el significante Europa está ligado a proyectos de legitimación de estructuras de poder y de construcción de identidad (Reverter Bañón, 2006, p. 51). No es casualidad que la expresión Estados Unidos de Europa, lema del federalismo europeo, se recoja en las páginas del periódico francés Le Moniteur en la significativa fecha de 1848.

Será, en resumidas cuentas, desde la revolución de 1789 a la guerra de 1914, en el transcurso del largo siglo XIX, ${ }^{3}$ cuando las diversas culturas políticas, liberalismo, nacionalismo y socialismo, modelen el mapa europeo y proyecten sobre Europa sus designios, en un momento en el que se atestigua el reforzamiento del Estado-nación que implica un doble proceso de homogeneización interna y singularización en el escenario europeo. Es entonces cuando se constituirán los Estados liberales europeos sobre el principio de la nacionalidad distintiva. Además, la homogeneización de los mercados, caso del Zollverein alemán, que desde 1834 establecería la abolición de aranceles en el seno de la Confederación Germánica y allanaría el camino para la unificación política de Alemania, confirma el proceso de homogeneización nacional y expansión internacional de los imperios europeos inherente al capitalismo decimonónico. No se olvide que en el siglo XIX se forma en Europa un sistema social uniforme basado en una cultura y unas instituciones comunes, un mundo basado en grandes imperios aristocráticos en el que los intereses nacionales y el destino de la Europa imperial se dan la mano. La articulación de una idea supranacional europea de alcance continental surge en diálogo permanente con la ordenación de Europa en Estados nacionales, lo que hace pensar con E. Gellner (2008, p. 131) que el internacionalismo augurado no hacía sino apuntalar la era del nacionalismo.

En suma, es en el conflictivo siglo de la transformación estructural de Europa cuando surgirán formas de hablar de la unidad continental o de configurar espacios de cohabitación política y económica alternativos que apelan a la nación como sujeto de la política estatal en un mundo Nos referimos a la trilogía clásica sobre el "largo siglo XIX" de Eric Hobsbawm, compuesta por La era de la revolución (1789-1848), La era del capital (1848-1875), La era del imperio (1875-1914).

Letras Históricas / Número 19 / Otoño 2018-invierno 2019 / México / pp. 127-156 / ISSN: 2448-8372 
cada vez más interdependiente. Europa se reivindica y teoriza cuando el ideal del nacionalismo hace tambalear los cimientos de las sociedades absolutistas, siendo un elemento tanto de reacción por quienes desean restablecer un orden fatalmente trastocado, como por quienes anhelan su unidad en un nuevo orden aún por nacer. En ese impasse se produce la transformación en la manera de pensar la comunidad nacional, de imaginarla como un mismo ente en virtud de una solidaridad de extraños que la debaten, reclaman o disputan. Es dentro de esa "revolución ideológica", como ha llamado A-M Thiesse (2010, pp. 11-12) a la irrupción del ideal de la nación en el mundo contemporáneo, como debe comprenderse la posibilidad de pensar Europa como unidad soberana.

Pero fue precisamente el nacionalismo el principal factor de desestabilización de la política europea e internacional entre 1880 y 1914 (Fusi, 2016, p. 15), ariete que terminaría derribando el mundo de los imperios, llevándose consigo el espíritu de familia europea de las antiguas dinastías, reemplazándolas por unas nuevas elites políticas postaristocráticas y nacionalistas (Traverso, 2009, p. 44). La Europa liberal del siglo XIX y su corolario, los grandes imperios coloniales que hacen su entrada en el nuevo siglo, se derrumbarían en la guerra de 1914, conflicto que marcaba el inicio del fin de la era europea del mundo.

\section{Guerra y paz. Europa en la guerra civil europea (1914-1945)}

"Nosotras, las civilizaciones, -escribió Paul Valéry en 1919- sabemos ahora que somos mortales". ${ }^{4}$ La reflexión identitaria del continente se exacerba, paradójicamente, en el momento en el que Europa salta en pedazos en 1914 y se ve desplazada de su posición hegemónica en el mundo. Como un gran Saturno, Europa devoraría a sus hijos en dos guerras mundiales, momento crepuscular al que Karl Kraus se refirió de forma elocuente como "los últimos días de la humanidad". 5

Lo que nos interesa subrayar es que la tarea de pensar Europa partía de un pensamiento agónico en clave civilizacional en el convulso contexto de entreguerras. Personalidades de primer orden en el pensamiento europeo como Oswald Spengler, Arnold Toynbee, José Ortega y Gasset o Martin Heidegger, entre otros, acometieron la radiografía espiritual de una Europa que degeneraba biológicamente como si de un órgano enfermo se tratara. Eran las secuelas de la Gran Guerra. En la introducción a La decadencia de Occidente, la monumental obra de Spengler publicada

\begin{tabular}{l|l}
${ }_{4}$ & Citado en Anderson, 2012, p. 503. \\
${ }_{5}$ & Les derniers jours de l'humanité. Citado en Traverso, 2009, p. 48.
\end{tabular} 
en dos tomos entre 1918 y 1923, se podía leer: “¿Hay una lógica de la historia? [...] La decadencia de Occidente [...] resulta, pues, un tema filosófico que, considerado en todo su peso, implica todos los grandes problemas de la realidad" (Spengler, 1998, pp. 29-30 y 108). La abigarrada filosofía de la historia que esbozaba Spengler culminaba con el llamamiento a la ley inexorable de la historia universal, tribunal del mundo, y se encomendaba al advenimiento de la raza más fuerte: al final, como aseveraba en una de sus frases más rotundas y recordadas, siempre sería un pelotón de fusilamiento quien salvara la civilización. Pero lo que era común a toda la nómina de pensadores era el empeño por interpretar la coyuntura de tribulación que atravesaba Europa en virtud de los tiempos largos de la historia que se interrelacionaban con ciclos políticos, económicos y militares, todo lo cual presentaba el fatal diagnóstico del crepúsculo de la civilización europea en detrimento de los decadentes nuevos mundos que la sucederían (Traverso, 2009, p. 50).

El lamento desesperanzado sobre el rumbo continental pautaba los escritos sobre Europa desde ópticas muy diversas, propuestas para encauzar la crisis que atravesaba la civilización europea y que propició el surgimiento de lo que Fritz Stern (1974) llamó Kulturpessimismus, un clima de pesimismo filosófico que acometía una reflexión reprobatoria de la civilización desde la cultura. Como ha señalado Terry Eagleton (2001, p. 25), "cuanto más agresiva y degradada parece la civilización, más se reafirma el carácter crítico de la idea de cultura". Así se entiende la advertencia del historiador francés Marc Bloch cuando señalaba que la teorización en torno a Europa tenía que ver con el teatro del miedo en que se había convertido la vida pública continental, un pavor originado por la pérdida de centralidad de Europa en el mundo y que encontraba motivos de alarma en la competencia industrial estadounidense en el oeste, en los alzamientos coloniales del sur, en el comunismo del este y en los conflictos nacionales en el interior de los países europeos (Anderson, 2012, p. 505).

Una de las diversas ideaciones de comunidad supranacional que alumbró la guerra de 1914 tenía que ver con una particular visión de Europa Central como centro neurálgico del continente. Mitteleuropa, literalmente Centroeuropa, esbozada en su obra homónima de 1915 por el amigo de Max Weber, el político liberal y protestante Friedrich Naumann, representaba una comunidad política en el centro del continente basada en una unión aduanera -Zollgemeinschaft- y en un vínculo cultural sobre el perfil del extinto Sacro Imperio Romano Germánico. Su núcleo consistiría en la confluencia tanto de la diligencia prusiana como de la herencia cultural austriaca, conformando una suerte de "super-Estado" -Oberstaat- en el que cada país mantendría su soberanía y capacitaría a Mitteleuropa para 
rivalizar con los imperios ruso y angloamericano (García Picazo, 2008, p. 240). La idea de Naumann, aunque en su origen fruto de un anhelo liberal de contrarrestar el militarismo prusiano del II Reich, pronto quedaría vinculada a nociones de pangermanismo. Mucho después, en el contexto de las revoluciones de terciopelo de 1989, Mitteleuropa sería reivindicada por intelectuales centroeuropeos que habían padecido el dominio soviético con el fin de afirmar su europeidad frente a una Unión Soviética que les habría condenado a vivir fuera de Europa durante cuatro décadas (Petrescu, 2011, pp. 55-86).

Ahora bien, fue el conde austríaco Richard Coudenhove-Kalergi quien tradujo en términos políticos el sentimiento de "decadencia de Occidente", auténtica preocupación epocal, cuando presentó su proyecto de Unión Internacional Paneuropea. El europeísmo esbozado por CoudenhoveKalergi pretendía extender la conciencia europeísta para convencer de la necesidad de unificar el continente bajo unas mismas instituciones políticas. A su manifiesto Pan-Europa de 1923, ampliamente difundido en los círculos intelectuales, reaccionaron figuras de primer orden en el mundo de las letras como Jules Romains, Paul Valéry, Sigmund Freud, los hermanos Mann, Stefan Zweig, Rainer Maria Rilke, Albert Einstein, H.G. Wells, Miguel de Unamuno, José Ortega y Gasset o Benedetto Croce, entre otros. El movimiento paneuropeo, no obstante, fue un proyecto elitista que no logró un apoyo de masas capaz de articular sus ideas en torno a la necesaria unidad política de Europa en virtud de una conciencia común (Crespo MacLennan, 2009, p. 48). A la hora de reivindicar Europa, Kalergi no podía ocultar su filiación aristocrática; la imagen de los intelectuales reunidos en torno a Coudenhove-Kalergi bien puede recordar los círculos ilustrados que siglo y medio antes habían teorizado sobre la paz perpetua.

Independientemente de su capacidad de movilización, conviene atender las tesis planteadas en el manifiesto Pan-Europa de 1923, un diagnóstico claro de la situación continental en el contexto resultante de la Gran Guerra:

Hoy en día, Europa no es ya ni el centro político de poder, ni el centro económico ni tampoco el centro cultural del mundo. El mundo se ha emancipado de Europa. [...] De ser el centro del mundo, Europa ha pasado a ser su periferia (Coudenhove-Kalergi, 2010, pp. 15-19).

La solución era una y clara: en un mundo que estaría dominado por varios imperios no europeos -a saber, el estadounidense, el británico, el ruso y el asiático-, la unidad de Europa era una tarea urgente, eclipsada como estaba en sus fronteras por la presencia bolchevique y por Gran 
Bretaña, el caballo de Troya del materialista mundo angloamericano. De la particular óptica europeísta de Kalergi se derivaba una idea que impregnaría la teorización liberal de Europa, a saber, que lo constitutivo de la civilización europea era un valor, la libertad, que se traducía en una forma de gobierno, la democracia.

Europa, en cuanto concepto político, abarca a todos los Estados democráticos (y semidemocráticos) de la Europa continental. [...] Al concepto político de Europa, para distinguirlo del concepto geográfico, yo lo llamo Pan-Europa (Coudenhove-Kalergi, 2010, pp. 41-42).

La misma afirmación liberal de Europa y la misma animadversión hacia el bolchevismo las mostraba el filósofo español José Ortega y Gasset, que en su obra La rebelión de las masas, publicada en 1930, relacionaba la crisis de la civilización europea en términos más culturales que políticos con el "advenimiento de las masas al pleno poderío social" (Ortega y Gasset, 1956, p. 41), unas masas que, al tomar el mando de los Estadosnación europeos, habían terminado por desmoralizar la realidad sustantiva del continente: la conciencia común europea. En el capítulo "¿Quién manda en el mundo?" abogaba por construir una unión europea revitalizada que significara un auténtico proyecto de vida en común y que, para realizarse, debería distanciarse tanto del nuevo mundo estadounidense como del asiático comunismo soviético. Como se verá más adelante, esta definición de Europa sobre criterios políticos y culturales excluyentes de los dos mundos extraeuropeos, Estados Unidos y la Unión Soviética, pautará la identificación posterior del primer embrión del proyecto supranacional en el contexto de la Guerra Fría.

Junto a Coudenhove-Kalergi, el ministro de Asuntos Exteriores francés Aristide Briand destacó como la figura que más enérgicamente apelaba a la necesaria unidad política del continente. Estadista destacado del tiempo de entreguerras, había sido uno de los valedores de la paz continental al promover tanto los Acuerdos de Locarno de 1925, por lo que recibiría el Premio Nobel de la Paz un año después, y el pacto Briand-Kellog de 1928 que lleva su nombre. En su discurso del 5 de septiembre de 1929 ante la Sociedad de Naciones abogaba por una federación europea y, más tarde, en mayo de 1930, presentaría un memorando que proponía la creación de una Unión Federal Europea, lo que constituyó el primer intento de trabajar en igualdad de condiciones con Alemania tras la paz de Versalles. "Entre los pueblos que están geográficamente agrupados debe existir un vínculo federal. Esta tarea no se hará de un día para otro, ni de un solo impulso, será una obra lenta" (BM, 
1930). ${ }^{6}$ La fórmula de Briand consistía en aumentar la cooperación entre los países europeos amén de crear un espacio económico común que garantizara la paz política, respetando en todo momento la soberanía nacional de los países integrantes y en cooperación directa con la Sociedad de Naciones. En sus propios términos, todo ello debía garantizar "el establecimiento de una unión pacífica permanente y cercana entre las gentes de Europa" (BM, 1930). La consecución de la paz universal, objetivo último a alcanzar, implicaba la pacificación de Europa, a la que se le presuponían afinidades raciales e ideas comunes de civilización. La pronta muerte de Briand en $1932 \mathrm{y}$ el inmediato ascenso de Hitler al poder impidieron que la idea del diplomático francés germinase, pero la tarea desarrollada no fue en vano.

Junto a estas propuestas de cariz liberal, surge desde la década de 1920 una corriente de pensamiento federalista cuyo punto en común reside en la reivindicación de una instancia supranacional que englobe el continente en una federación, unos United States of Europe, enarbolados por figuras y agrupaciones de índole diversa y con finalidades dispares. Luigi Einaudi, Arthur Salther, Vladimir Woytinsky, Alfred Vanderpol, Tulio Martelli, Charles Gide, Gastón Riou o Ivor Jennings apelaron a la unidad continental, bien de forma individual o desde asociaciones federalistas que afloraron a partir de la primera postguerra como L'Ordre Noveau, La Fédération, Cahiers de la République Moderne o Esprit en Francia, la belga Jeune Europe, en la que militaría Paul-Henri Spaak, o la británica New Commonwealth Society (Folguera, 2009, pp. 17-53).

El punto en común de tan dispares iniciativas, que tendrá un papel significativo en el contexto de las resistencias nacionales en la segunda contienda mundial, consistía en la convicción de que la unidad de Europa implicaba garantizar la paz. Así, se reproducen los lugares comunes que justifican Europa y la presentan como necesidad ineludible: en tantos escritos del periodo se habla de la unión moral del continente, de la comunidad de destino, de la salvación espiritual, del desfallecimiento de Europa, expresiones que evocan ecos nietzscheanos y que se justifican sobre una idea de civilización compuesta de criterios étnicos, pero fundamentalmente espirituales y morales.

Sin embargo, si bien el federalismo llamaba a la unidad europea para pacificar el continente, la revolución conservadora de la década de 1930 reivindicó una Europa vigorosa como única alternativa a la doble amenaza del bolchevismo y del capitalismo estadounidense orquestada por la conspiración del judaísmo internacional. En la cosmovisión nacionalista

${ }_{6} \quad$ Todas las traducciones son propias. 
de un pangermanismo fascistizado, la unidad de Europa como única depositaria de una moralidad auténtica era una necesidad que exigía trascender las fronteras nacionales en busca del propio espacio vital (Judt y Snyder, 2012, p. 175). En suma, el anhelo de unidad supranacional, de un signo o de otro, estaba atravesado por el malestar de la cultura de entreguerras. Una nueva guerra mundial cerraría el ciclo de la guerra civil europea ${ }^{7}$ y consumaría definitivamente la decadencia de Occidente.

\section{Neorrealismo europeo: Europa, año cero}

"I wish to speak to you today about the tragedy of Europe". Con estas palabras se dirigía Churchill a su auditorio en el discurso pronunciado en la universidad de Zúrich en septiembre de 1946. La guerra, que había enfrentado diferentes visiones del mundo y modelos de civilización que disputaban el destino de Europa, había supuesto un profundo desgarro de conciencia en el pensamiento europeo. Lo diría Sartre en 1949: "Sabemos lo que es una ciudad mutilada y que esa ciudad mutilada es europea". 8 Pero el veterano estadista británico iba a plantear algo que, aseguraba, sorprendería a su auditorio: "A pesar de todo, aún hay un remedio. [...] ¿Cuál es ese eficaz remedio? Es volver a crear la familia europea [...] Tenemos que construir una especie de Estados Unidos de Europa. [...] ¡Levantemos Europa!" (Brugmans, 1972, pp. 367-371).

Ahora bien, la unidad de Europa invocada en 1945 evocaba el imaginario de un continente sometido con mano de hierro por el Reich alemán y organizado por una hegemónica raza germana, una noción que destilaba un ferviente antibolchevismo y el deseo de arrancar la raíz liberal y democrática del terreno europeo, lo que despertaba el recelo de escandinavos e ingleses sobre la idea de unidad continental (Judt y Snyder, 2012, p. 335). El nazismo, no se olvide, había supuesto una unidad europea de facto allí donde la economía de guerra nazi había implicado la unión de aduanas y la integración forzosa de mercados orientados a fines bélicos (Mazower, El concepto de "guerra civil europea" ha sido utilizado por varios historiadores para estudiar el periodo comprendido entre las dos guerras mundiales, de 1914 a 1945. Uno de los usos más controvertidos ha sido el del historiador alemán Ernst Nolte, que lo empleó para subrayar la imbricación entre el bolchevismo y el nazismo. Para un análisis de su uso en los trabajos de varios historiadores, consultar el apartado "Interpretaciones" en Traverso, 2012, pp. 31-37.

8 Défense de la culture française par la culture européenne, conferencia pronunciada el 24 de abril de 1949 en el Centro de Estudios de Política Extranjera en París. Citado en Cohen Solal, 2005, p. 121.
} 
2001, pp. 174-178). Todo ello condicionaba la representación de Europa posterior: en los heterogéneos círculos federalistas, a la ambición nazi de una Europa regida por una raza aria debía oponerse una Europa federal constituida por los pueblos liberados.

Europa se pensaba ahora desde el triunfo de la nación resistente y victoriosa; el antifascismo era la marca de nacimiento del mundo posterior a 1945, auténtica "religión civil" en muchos de los países liberados (Traverso, 2009, p. 19). Las narrativas nacionales de postguerra ensalzaban la gesta heroica del pueblo liberado de las garras del enemigo, lo cual permitía exonerar del peso del pasado reciente en una historia que, para ser reconfortante, debía acentuar las proezas de la contienda y extirpar el fascismo del curso natural de la historia nacional, olvidando, de paso, la connivencia de la población en los crímenes de guerra (Berger, 2005, pp. 629-678). Era el momento propicio para que los resistentes antifascistas, casos de Francia e Italia, hablasen en nombre de la nación y escribieran la historia nacional en clave de liberación.

Ahora bien, debe pensarse hasta qué punto al reconocerse en el mito común de la lucha antifascista los países victoriosos podían conjugar la heroicidad nacional de la patria liberada con la necesidad de construir una Europa unida. A pesar de que, como apunta J. P. Fusi (2016, p. 237), el descrédito del nacionalismo no era en 1945 un hecho universal, sino un hecho exclusivamente europeo, la reorganización del mapa de postguerra en Europa se acometería partiendo de los intereses nacionales y del empeño en reconstruir los extenuados Estado-nación sobre medidas que garantizaran la estabilidad económica, ${ }^{9}$ auténtica urgencia en la inmediata postguerra anterior al anhelo de unidad europea (Judt, 1996, p. 15; Mazower, 2001, p. 228). Debe tenerse en cuenta que la proyección de una unión continental, de unos United States of Europe, tan teorizados como hemos visto desde el siglo anterior como presentes en los discursos de la política de postguerra fue, en palabras de M. Mazower (2001, p. 228), más que un programa político, una "herencia ética" compartida en los círculos de resistencia para contrarrestar el Nuevo Orden Europeo nazi.

Sea como fuere, la segunda guerra mundial actuó como percutor en la articulación de una Europa alternativa a la que el nazismo quiso dibujar. En plena guerra había nacido el programa político del federalismo, el $\mathrm{Ma}$ nifesto di Ventotene (Spinelli y Rossi, 2001) escrito en cautiverio en 1941 y publicado en 1944 por el excomunista italiano Altiero Spinelli, junto a Ernesto Rossi y Eugenio Colorni, en la prisión de la isla italiana que le da nombre. De repercusión limitada debido a su escasa distribución, el texto

$9 \quad$ Es la tesis de la obra clásica de A. S. Milward, 1992. 
ofrecía un diagnóstico claro: si el imperialismo era el problema de una Europa abocada a la destrucción por el hambre voraz de unos Estados nacionales poseídos por impulsos depredadores, la confederación europea aparecía como una solución ineludible para terminar con la guerra. La paz continental sólo podría alcanzarse si se trascendía el Estado-nación. El manifiesto sería la base del Movimiento Federalista Europeo, creado en Milán el 27 y 28 de agosto de 1943 por los mismos Spinelli, Rossi y otros antifascistas tras la caída de Mussolini, que tendría eco en el seno de las resistencias de Bélgica y Francia. En los años sucesivos se celebrarían reuniones, como la de Ginebra en 1944, de la que surge el Manifeste de la Résistance Européenne, la de Hertenstein en septiembre de 1946, en Luxemburgo, un mes después, la constitución del United Europe Movement el 14 de mayo de 1947 o la reunión de los demócrata cristianos asociados en las Nouvelles Équipes Internationales (NEI) el 3 de junio de 1947, entre otros.

Pero si hay un acontecimiento determinante en la historia del europeísmo previo a la primera construcción europea ése es el Congreso de Europa, celebrado entre los días 7 y 10 de mayo de 1948 en La Haya, el mayor encuentro de las asociaciones europeístas activas desde los años veinte y treinta tras 1945. Fruto del multitudinario congreso sería la creación del Movimiento Europeo, organismo privado no gubernamental que articularía las demandas de las agrupaciones convenidas, constituido en Bruselas el 25 de octubre de 1948, junto a la creación, en 1949, del Consejo de Europa y la apertura de la primera institución para el estudio de la integración europea, el Collège d'Europe, que se inauguró en la ciudad belga de Brujas en 1950 (Folguera, 2010, pp. 93-94). En la resolución del Comité Cultural del Congreso de La Haya, presidido por el español Salvador de Madariaga, se recoge la declaración en clave identitaria de la comunidad evocada:

Creyendo que la Unión Europea no es ya una idea utópica sino que ha devenido necesidad, y que sólo puede establecerse sobre una base duradera si es fundada sobre una unidad genuina y viva;

Creyendo que esta verdadera unidad, en conocimiento de nuestras diferencias nacionales, ideológicas y religiosas, debe encontrarse en la herencia común de los valores cristianos y otros valores espirituales y culturales y en nuestra lealtad común a los derechos fundamentales del hombre, especialmente a la libertad de pensamiento y de expresión (CE, 1948, p. 48). 
La Europa federal se asentaba sobre una doble herencia, la cristiana y la ilustrada, que dibujaban las líneas programáticas sobre una moral y un sentido cívico cimentados en los derechos inalienables del individuo. Lo que interesa subrayar es la existencia de una declaración moral de lo que Europa es; Europa, una geografía imprecisa, es reconocida como idea moral, suelo axiológico. Es, sin duda, una Europa en guerra contra la guerra, una unión no carente de cierto sentido de misión, del deber de asegurar la paz en virtud de unos valores que se presumen propios y que, para la pacífica marcha del mundo, deben ser extendidos a toda la humanidad. "La dignidad humana es el mayor logro de Europa, la libertad su máxima fortaleza. Ambas están en juego en nuestra lucha. La unión de nuestro continente es necesaria no sólo para la salvación de las libertades que hemos ganado, sino también para la extensión de sus beneficios a toda la humanidad." De esta unión dependen el destino de Europa y la paz en el mundo, auténtico sentido de "esta noble causa, que ofrece la última oportunidad de paz y la única promesa de un gran futuro para esta generación y las que le sucedan" (CE, 1948, p. 51).

La retórica es marcadamente paneuropea y, puede decirse, eurocéntrica, al tomar como eje de los asuntos internacionales el sino de Europa. Pero el énfasis en la centralidad axiológica del Viejo Mundo no hace sino evidenciar una realidad: la unidad de Europa a la que se apela es una teorización proveniente del periodo de entreguerras, pero su realización concreta debe encajar en el nuevo contexto bipolar de postguerra. Dicho de otro modo, y de forma paradójica, el paso del anhelo europeísta a la creación de las instituciones necesarias sólo será posible en el contexto de la Guerra Fría, cuando Europa ha perdido la centralidad en el escenario mundial.

\section{Sistema de partidos y padres de Europa}

La Europa unida es un producto de los cambios en las relaciones internacionales que se producen en 1945. W. Loth (2008, pp. 9-27) ofrece un modelo de comprensión del proceso de construcción europea basado en cuatro ideas-fuerza o condicionantes que explican la posibilidad de la Europa que surgió en la inmediata posguerra: la voluntad de preservar la paz entre estados soberanos, la preocupación latente por la resolución de la "cuestión alemana", la necesidad de los mercados nacionales de ensancharse e integrarse en áreas económicas más amplias y, por último, el deber de autoafirmación de una Europa relegada a segundo plano en el contexto internacional a resultas del nuevo conflicto bipolar. Pero los factores internacionales deben comprenderse en relación a las dinámicas 
domésticas de los países que conformarán la primera unidad europea de la que parten los protagonistas que lideran la iniciativa.

La paternidad del proyecto europeo se ha asociado a la obra de un puñado de hombres, los pères fondateurs de l'Europe, cuya nómina incluye a Monnet, Schuman, Adenauer, Churchill, Spaak o De Gasperi. Fueron las cabezas visibles del panorama político de la postguerra, hombres dotados de cierta aura de santidad al haber asumido durante la guerra la tarea de liderar la resistencia de sus países hacia la liberación. Personalidades como Schuman, criado y educado entre Luxemburgo y Metz, o De Gasperi, oriundo de Trieste, habían nacido en territorios limítrofes, eran frontaliers, hijos de regiones en disputa que en cuestión de décadas habían cambiado de dueño por los designios de la guerra. Se debe comprender, por tanto, que la experiencia bélica influyó en la sensibilidad marcadamente cristiana de quienes decisivamente impulsaron la integración continental (García Picazo, 2008). Adquieren por tanto su significación como padres fundadores de Europa dentro del clima de la postguerra y del horizonte político que se presenta entre el fin de una contienda y el comienzo de otra.

Los gobiernos de unidad nacional surgidos en la guerra y sostenidos sobre el relato común de la resistencia no tardaron en dejar paso a la reconstrucción del sistema de partidos en la inmediata postguerra. Proyectado sobre Europa, el proceso venía a afirmar las formas de hacer política en clave nacional y a desechar la propuesta federalista de trascender el marco estatal (M. Cabrera, S. Juliá y P. Martín Aceña, comp., 1992, p. 44). En términos políticos, no tardó en definirse feudo demócrata-cristiano al amparo de unos Estados Unidos que sirvieron de paraguas económico -Plan Marshall- y militar -OTAN-, con unos partidos comunistas que fueron apartados de sus respectivos gobiernos a partir de 1947 en el contexto del conflicto bipolar.

Pero el triunfo de la democracia cristiana no era únicamente un designio de la guerra fría. Si bien la Gran Guerra tuvo un efecto catalizador del radicalismo y la politización que caracterizarían al periodo de entreguerras, a la segunda contienda mundial le sucedió un radical anhelo de normalidad. En las antípodas de cualquier reivindicación utópica o subversiva del orden social, de toda retórica radical de conquista del poder o de recuperación de la grandeza de la patria, la democracia cristiana hacía hincapié en la reconciliación y en la estabilidad nacional con base en los valores de la familia, la fe y la reforma moral y política del cuerpo social. Con un lustre antifascista intachable, la vinculación a la Iglesia católica de los partidos cristianodemócratas era una garantía anticomunista en el escenario polarizado de postguerra. 
Volvía a primera plana política aquello que había sido engullido por el fascismo y el comunismo en la década anterior, el moderantismo político que tenía sus valedores de postguerra en la socialdemocracia y en el catolicismo militante de raigambre liberal. Un vistazo a las personalidades políticas de los años posteriores a 1945 muestra la predominancia de los líderes demócrata-cristianos y socialdemócratas: Konrad Adenauer en la República Federal Alemana, Georges Bidault en Francia y Alcide De Gasperi en Italia, junto a los socialistas Paul-Henri Spaak en Bélgica, Karl Renner en Austria o Tage Erlander en Suecia. Se observa de forma nítida la genealogía política de los padres de Europa, una Europa que, como apuntó Jorge Semprún (2006, p. 282), fue construida contra el fascismo y contra el comunismo en el marco postbélico de la Europa liberal.

Desacreditado el fascismo en la guerra, la Europa unida sería iniciativa demócrata-cristiana auspiciada por la aceptación socialdemócrata de un capitalismo reformado. Además, reconstruir materialmente Europa a través del Plan Marshall era una forma de luchar contra la miseria de la postguerra, auténtico caldo de cultivo para los partidos comunistas en Italia, Francia o Bélgica y factor fundamental para convencer a la administración Truman de la puesta en marcha del plan de auxilio europeo (Fontana, 2011, pp. 68-72). Ahora bien, la profunda huella dejada por la democracia cristiana conllevaba una consecuencia importante a efectos de identidad: existía, sobre todo en Escandinavia y Gran Bretaña, el temor a que el peso que los valores cristianos de los padres de Europa hiciera de ella una suerte de alianza católica, una "Europa vaticana" (García Picazo, 2008, p. 47) o "internacional negra", en palabras de Kenneth Younger, asesor de Ernest Bevin, unas instituciones comunitarias interesadas en reconstruir los países europeos sobre un modelo económico neocorporativista (Judt y Snyder, 2012, p. 336).

Con la puesta en marcha del Plan Marshall y de la OTAN en el bloque capitalista, y del COMECON y el Pacto de Varsovia en el bloque comunista, quedaba conformado el escenario geopolítico de la Guerra Fría. A efectos domésticos, es decir, europeos, la partición del mundo se escenificó en la fractura de Europa sobre un eje Oeste-Este que dividía una vertiente occidental capitalista de una oriental comunista. Esta profunda mutación de las relaciones internacionales en apenas un lustro llevaba aparejada una consecuencia que afectaba la manera de imaginar el mapa europeo: la vertiente occidental se arrogaba el título europeo, definida en oposición al mundo comunista del Este, que bajo este sufijo quedaba excluido de Europa al denotar su condición de marioneta dirigida desde el Kremlin (Dinan, 2004, p. 23). 
En definitiva, la relación de la Guerra Fría con la definición identitaria de la primera Europa unida es crucial; Europa comienza a caminar asida de la mano de Estados Unidos y a su política de containment contra los intereses soviéticos. Como ha señalado M.T. Bitsch (1998, p. 504), Europa verá su identidad supeditada a la necesidad de afirmar su modelo propio en un contexto bipolar: "Mais à cette époque où l'Europe est divisée en deux blocs, la question de l'identité européenne semble oblitérée par la question idéologique". ${ }^{10}$

Se entiende así que el Tratado de Bruselas, firmado el 17 de marzo de 1948, encaminado a asegurar la cooperación intergubernamental en materia de defensa entre las partes contratantes, a saber, los países del Benelux -Bélgica, Holanda y Luxemburgo-, Francia y el Reino Unido, antecedente de la alianza de seguridad occidental, la OTAN, se justificara en virtud de unos valores determinados: "los derechos humanos fundamentales, la dignidad y el valor de la persona [...], los principios de la democracia, la libertad personal y política, las tradiciones constitucionales y el imperio de la ley" (BT, 1948, p. 3). En el artículo tercero se apelaba a la dimensión cultural compartida, a una "civilización" común (BT, 1948, p. 5). La misma llamada a la "sociedad humana y civilización" compartidas se explicita en el preámbulo del Tratado de Londres, firmado el 5 de mayo de 1949, que fija las bases del Consejo de Europa, donde se menciona "el compromiso con los valores espirituales y morales que son la herencia común de sus gentes y verdadera fuente de la libertad individual y política y del imperio de la ley, principios que forman la base de toda democracia genuina" (SCE, 1949). Es en este contexto y en esta línea retórica condicionada por el conflicto bipolar donde debe enmarcarse la iniciativa que hará posible acometer la primera construcción europea.

\section{Construir Europa}

De entre los problemas ante los que se enfrentaba el continente en la segunda postguerra el más delicado era la llamada "cuestión alemana", esto es, la necesidad de reconstruir el continente sobre las bases de una Alemania recuperada que no supusiera una nueva amenaza en el equilibrio de fuerzas continental. Las posiciones sobre el asunto alemán distaban de ser unánimes. La prioridad estadounidense era la recuperación del Viejo Continente a través de un reavivamiento de la economía europea, lo que pasaba por auxiliar a Alemania tanto económica como

10

"Pero en esta época en que Europa está dividida en dos bloques, la cuestión de la identidad europea parece haber quedado borrada por la cuestión ideológica".

Letras Históricas / Número 19 / Otoño 2018-invierno 2019 / México / pp. 127-156 / ISSN: 2448-8372 
militarmente. La idea aterrorizaba a Francia, profundamente desconfiada de sus vecinos allende el Rin, con quienes en tres ocasiones -1870 , 1914 y 1939- había entrado en guerra desde la proclamación del II Reich. La posición francesa era clara: tan sólo una Alemania económicamente dependiente, exportadora de sus materias primas y militarmente doblegada podía asegurar la paz del continente y la prosperidad de la siderurgia francesa. Alemania, por su parte, en una posición de inferioridad, anhelaba ser reconocida en la comunidad internacional. Los británicos, con Churchill como héroe de guerra, defendieron la unidad europea, una unión continental necesaria para contener el comunismo soviético de la que Gran Bretaña se guardaba de participar, volcada en su tendencia atlantista cercana a Washington y en la salvaguarda de un imperio menguante. Los países del Benelux, principalmente Holanda, anhelaban situarse bajo el ala protectora del Reino Unido, temerosos de una potencial hegemonía francesa.

Francia siguió la idea de Jean Monnet, un errático empresario que había hecho sus negocios en el convulso periodo de entreguerras, un hombre cercano al general De Gaulle en el exilio que ideó la maniobra consistente en la creación de una autoridad común supranacional que gestionase de manera conjunta las industrias del carbón y el acero francoalemanas. La solución permitía poner fin al conflicto de intereses nacionales de la inmediata postguerra: Francia obtenía el carbón renano para vitalizar su dependiente siderurgia y Alemania Occidental era reconocida en el concierto internacional como parte integrante del bloque capitalista, solución que agradaba a los Estados Unidos en la lógica de la Guerra Fría contra los soviéticos.

La Declaración Schuman, pronunciada por el ministro de Asuntos Exteriores francés Robert Schuman el 9 de mayo de 1950 en el parisino Quai d'Orsay se ha interpretado como el acta de nacimiento de la Europa unida. ${ }^{11}$ En verdad, el acontecimiento supone la presentación pública de la iniciativa monnetiana, consistente en la creación de la CECA, esto es, la Comunidad Económica del Carbón y el Acero, un organismo supranacional encargado de gestionar el mercado común del sector energético, mediante la supresión de barreras y tarifas aduaneras de los países in-

11 La Unión Europea celebra el 9 de mayo el Día de Europa, aniversario del día en que Schuman concedió la célebre rueda de prensa que anunciaba el nacimiento de la CECA. Las instituciones comunitarias celebran "la paz y la unidad del continente", y para tal fin se organizan debates, conferencias y conciertos encaminados a pensar y compartir la idea de Europa. Más información en: http://europa.eu/european-union/about-eu/ symbols/europe-day_es 
tegrantes, los que desde 1957 formarían la Europa de los seis: Francia, la República Federal Alemana, Italia y los países del Benelux -Bélgica, Holanda y Luxemburgo-.

La creación de la CECA, ideación que carecía de antecedentes históricos, era fundamentalmente una solución europea al problema francoalemán y, en última instancia, a la necesidad francesa del carbón alemán (P. Anderson, 2012, p. 39). Todo ello permite comprender que las motivaciones últimas del Plan Monnet, presentado como una maniobra de tipo económico, respondían a intereses políticos y eran, sobre todo, sumamente pragmáticas, originadas de la necesidad de recuperar la economía nacional gala. Pero desde un punto de vista del análisis del discurso en clave identitaria lo que nos interesa subrayar no es tanto lo que constituye, sino la finalidad sobre la que se justificaba la acción tomada. Es en los primeros párrafos de la célebre declaración donde Robert Schuman explicita la motivación de la propuesta:

La paz mundial no puede salvaguardarse sin unos esfuerzos creadores equiparables a los peligros que la amenazan. [...] La contribución que una Europa organizada y viva puede aportar a la civilización es indispensable para el mantenimiento de unas relaciones pacíficas. [...] Europa no se construyó y hubo la guerra. [...] Europa no se hará de una vez ni en una obra de conjunto: se hará gracias a realizaciones concretas, que creen en primer lugar una solidaridad de hecho (DS, 1950).

No obstante, hubo que esperar once meses desde la rueda de prensa en la que Schuman hizo pública la estrategia ideada por Monnet para que ésta se pusiera en marcha. El 18 de abril de 1951 se reunieron en París los ministros de Asuntos de Exteriores de los seis países que conformarían la primera comunidad, la CECA. De la cumbre surgió el Tratado de París, documento que pasó a regir el funcionamiento de las instituciones europeas. Ahora bien, el preámbulo de la resolución reproduce la misma narrativa implícita en la declaración Schuman: la necesidad de construir Europa a través de "realizaciones concretas" para evitar otra guerra en el seno de la civilización europea, lo que equivale, se deriva, a la garantía de la paz mundial.

El discurso reproducía el tropos del continente amenazado que debe superar los impulsos de la sinrazón que habitan en su seno; Europa, pues, debía ser exorcizada de su pasado inmediato. Las "rivalidades históricas" no podían determinar el presente y futuro del continente, la tradición no podía perdurar, lo sido no podía seguir siendo. El acuerdo era la muestra de que el talante político podía y debía cambiar el curso de la 
historia. A partir de entonces, la Europa de la cooperación tomaba el relevo a la Europa de la competencia. En una palabra, tanto en la rueda de prensa ofrecida por Schuman como en el preámbulo del Tratado de París, la argumentación era clara: si Europa no se había construido y su consecuencia lógica había sido la guerra, se infería que construir Europa era asegurar la paz. Como ha señalado M. Ahijado Quintillán (2000, p. 166), "la construcción monnetiana en germen trataba de preludiar una nueva identidad europea y una legitimidad depurada de su pasado reciente".

Pero el olvido de la barbarie reciente era una invitación a la búsqueda de un tiempo perdido. En este sentido, no faltaron iniciativas para dotar de trascendencia al primer acuerdo comunitario. En octubre de 1953 se convocó bajo los auspicios del Consejo de Europa una "Mesa Redonda de Europa" en torno al "problema espiritual y cultural de Europa considerada en su unidad histórica y los medios para expresar esa unidad en términos contemporáneos". Participaron los eminentes académicos Toynbee, Kogon y Loefstedt, el diplomático y entonces presidente de la Asamblea de Naciones Unidas Van Kleffens, los políticos De Gasperi y Schumanm, y el suizo Denis de Rougemont, que moderó el debate. Recordando el encuentro, Robert Schuman reflexionaba en sus memorias sobre la Europa naciente:

Queremos volver a una unidad como la que existió en el pasado bajo la égida de Roma, pagana primero, cristiana después. Esa unidad se deshizo como consecuencia de la emancipación del pensamiento, del maquinismo y del progreso técnico. La Europa dividida no ha sabido dar al mundo contemporáneo el "mensaje espiritual" que necesitaba. Se trata de saber si Europa podrá ocupar otra vez el sitio que ocupó en el pasado; saber si podrá orientar la evolución de la humanidad, no por medio de una hegemonía de poder militar o económico, sino por el esplendor de su espíritu (Schuman, 2006, p. 155).

En definitiva, al naciente proceso de integración europea emprendido por la senda económica le fue aparejado una tarea de legitimación desde el pensamiento filosófico. Y se hizo como se había realizado en el periodo de entreguerras, es decir, desde la reflexión metafísica sobre la conformación espiritual y moral de una Europa tan crepuscular como naciente. La búsqueda del ser de Europa, de una esencia europea lejana de cualquier campo de concentración y cercana a algún ideal humano abstracto dio cobertura a la propensión por los relatos teleológicos sobre un supuesto carácter excepcional de Europa. Salvador de Madariaga, Karl Jaspers, José Ortega y Gasset, Luis Díez del Corral, Denis de Rougemont o Jean- 
Baptiste Duroselle, entre otros, acometieron la tarea de aunar contingencia y trascendencia, asegurando, en suma, la continuidad de la narrativa de la excepcionalidad europea.

\section{Conclusiones}

Si hay una fecha que sirve de gozne entre las dos caras antitéticas de un siglo al que Hobsbawm bautizó como una era de los extremos, ése es el simbólico año de 1945, que marca el fin de una era de catástrofes e inicia una edad de oro del capitalismo. ${ }^{12} \mathrm{Es}$, por tanto, del fin de la guerra en 1945, del fracaso moral de Europa, de donde partió su reconstrucción política. Como ha sugerido A. Moreno Juste (1999, p. 164), "la Europa política parece construirse sobre las ruinas de la Europa espiritual".

Lo que debe subrayarse es que esa Europa política sólo se puso en marcha tras dos conflagraciones mundiales de origen europeo. La paz de 1945 no se cimentará sobre el perdido concierto europeo, a la manera pergeñada por los teóricos ilustrados de los siglos XVIII y XIX, sino sobre el equilibrio de terror atómico en un mundo que pierde su tradicional centro de gravedad tras la guerra civil europea (Traverso, 2009, p. 48). Estar alineada en el bloque occidental, auxiliada por el Plan Marshall y aliada en la OTAN, hacía de la primera Europa unida parte integrante del "mundo libre" capitalista, que se definía sobre los principios de la democracia, la libertad y los derechos del individuo. Pero antes de entregar el testigo de la historia al otro lado del Atlántico, Europa se afirmaba sobre una identidad singular, entendida como depósito de historia y civilización y eje axiológico del equilibrio mundial; la reconciliación continental hacía de la Europa naciente una comunidad moral. Así, los discursos de los padres fundadores y los primeros tratados reproducen los tropos ilustrados de la salvaguarda de la civilización europea, asentada en un corpus de creencias, leyes y costumbres comunes, un faro cuya luz se afirmaba necesaria para guiar el destino de los pueblos que quisieran vivir en libertad. Contingencia y trascendencia se aunaban en el discurso europeísta de postguerra, recogiendo de la herencia ilustrada su argumento central: la paz mundial sólo se alcanzaría con la paz de Europa, cuna de la libertad y árbitro del concierto internacional.

La Europa que representaba la nueva construcción política era, sobre todo, un consenso post-totalitario, reflejo de la visión liberal y humanista

The Age of Extremes, una "era de extremos", es la expresión con la que Hobsbawm nombra el "corto siglo xx", cuya traducción en español, Historia del siglo XX, omite el sentido del título original. 
que condenaba la fatídica primera mitad de siglo como un tiempo de barbarie, ya fuera de signo fascista, nacionalsocialista o comunista, que por propia inconsistencia se había extinguido para que Europa pudiera ser reconducida por el curso natural del progreso y la democracia. De manera significativa, el título del libro escrito por Luis Díez del Corral en 1953 se titulaba El rapto de Europa, una interpretación de la historia reciente del continente en forma de caída imprevista, un desvío súbito que la civilización había experimentado y que debía superar para retomar el camino al que estaba predestinada.

Mediante la alusión constante a la tragedia y la destrucción recientes, la importancia trascendental de Europa, su sentido de misión, se sustentaba en su fragilidad. Si bien no había antecedentes políticos de una construcción supranacional de tal calibre, aquella Europa unida no emergía ex nihilo; como ha apuntado J.P. Fusi (2016, p. 246), la unidad europea fue, más allá de una estrategia calculada o una suma de intereses particulares de países devastados, un ideal político que partía de la unidad básica de la cultura y el espíritu europeos para aspirar a la creación de un nuevo orden capaz de garantizar estabilidad internacional, libertad política, desarrollo económico y bienestar social. Construir Europa significaba garantizar la paz continental y mundial. La democracia, las libertades fundamentales y los derechos humanos se afirmaban de forma contingente tras el fin de la guerra, pero suponían la afirmación de un legado intelectual que, se ha visto, se gestó a lo largo de la contemporaneidad.

Enfatizamos, por tanto, que Europa como unidad institucional es producto contingente del contexto de la segunda postguerra, una Europa de los Estados erigida en el consenso democristiano dentro del contexto internacional de la Guerra Fría. Este hecho no debe llevarnos a olvidar los otros caminos que no se transitaron; las muchas Europas soñadas en los años de entreguerras, la federal, la de las regiones, la de los pueblos y naciones, los Estados Unidos de Europa, proyectos que no cuajaron por la correlación de fuerzas políticas y condicionantes de la postguerra. Francia y Alemania pautaron el modelo futuro, un pacto binacional entre Estados asociados a partir de la convergencia de intereses nacionales en sectores energéticos específicos, el método Monnet consistente en combinar federalismo e intergubernamentalismo. Pero para ello, el ideal político de la unidad europea era, más que una retórica, un acicate para reordenar el mapa europeo sobre nuevos consensos.

La identificación de Europa como discurso debe conducirnos a reflexionar sobre las aporías de la identidad. A lo largo de estas páginas se ha visto que, a escala supranacional, la reflexión sobre Europa generada en el siglo xx ha reproducido el esquema narrativo de las comunidades 
nacionales: auge, caída y renacimiento de un continente que se toma como comunidad de destino, ${ }^{13}$ como genuina civilización, que se autodefine en el relato de la Ilustración y de unos valores compartidos que tímidamente se vinculan con la común herencia cristiana. La construcción europea iniciada a partir de la declaración Schuman de 1950 se pone en marcha desde la tradición tecnocrática identificada por Perry Anderson, y sobre la estrategia funcionalista ideada por Jean Monnet. Ese legado propio del humanismo liberal está presente desde el inicio de la construcción comunitaria y es recogido, tiempo después, en la Declaración de Copenhague de 1973, que concreta la defensa de "los principios de la democracia representativa, el imperio de la ley, la justicia social -que es el fin último del progreso económico- y el respeto de los derechos humanos", todos ellos, se dice, "elementos fundamentales de la Identidad Europea" (DEI, 1973).

Pero fundamentalmente el éxito -o fracaso- del relato europeo ha consistido en su inercia. La construcción europea se ha vinculado a una narración de la historia de Europa que progresaba de forma lógica hacia su autorrealización. El riesgo en la excesiva confianza en esta narración reside, siguiendo a E. Traverso (2009, p. 17), en que una sensibilidad post-totalitaria celebre el humanitarismo asociado a Europa como el corolario de un liberalismo triunfante e inmune a las ideologías que un día la disputaron; ello no haría sino presentar a Europa desposeída del sentido trágico que la hizo posible, lo que dejaría a la Unión Europea desprovista de los mecanismos de análisis para comprender los relatos alternativos que la disputan y desnudan. Si la Europa construida ha encontrado en el consenso el impulso necesario para alcanzar cada nueva ampliación, no debería desatender los disensos que habitan en su seno.

Más aún ahora, en el momento más serio de impugnación del proyecto europeo y de crisis de su relato. Sabiendo que Europa como unidad económica y política es un producto de la Guerra Fría que le sobrevive, no está tan claro si persiste el aura metapolítica con la que se ha definido desde su momento inicial y que le ha diferenciado de otro tipo de unión comercial o arancelaria. T. Judt (1996, p. 34) creía que el éxito de la primera comunidad europea residía en haber creado una "ética ontológica de comunidad política que se aplica en retrospectiva para exponer los beneficios conseguidos hasta entonces y justificar posteriores esfuerzos unificadores". En otras palabras, ha existido una voluntad de justificar una comunidad política sobre la base de un relato o trama de identidad

\footnotetext{
${ }_{13}$ El término lo ha empleado Edgar Morin en Morin, 2009.
} 
asociada no tanto con una o varias culturas nacionales, sino con unos valores abstractos de espectro universal

Aquí se ha analizado la genealogía histórica de un discurso resultante de la contemporaneidad concretado en la Europa realmente existente en 1945. Hoy, clausurada la modernidad europea y expuesta a la anomia de los tiempos postmodernos, la Unión Europea debe replantearse en perspectiva histórica el discurso de su propia identidad. Si el proyecto europeo quiere pervivir, le convendría confeccionar un relato creíble, no sin antes acometer lo que G. Delanty (1995, pp. 1-15) ha denominado la "deconstrucción de la falacia eurocéntrica", la implícita asociación de la idea de Europa con normas válidas universales y con el mito de su unidad, un mito que, como advirtió S. Hall (1991, pp.18-19), siempre precisaría de la figura del Otro, los exteriores constitutivos de la identidad, ya fueran éstos los inmigrantes, los refugiados, los fundamentalismos religiosos o cualquier otra expresión identitaria dentro de la lógica del antagonismo cultural.

El propio T. Judt (1996) se mostró escéptico respecto del futuro de la unión, sospechando que tal vez la construcción europea había sido una gran ilusión, un relato de promesa demasiado ambicioso que no sobreviviría a la extinción del contexto que la hizo posible, incapaz, en fin, de acometer las dificultades que la acechaban después de 1989-1991: la ampliación al Este, la unificación alemana y la unificación monetaria, entre otros. La invocación acrítica del mito de Europa, alertaba, se convertirá en un impedimento para saber reconocer sus problemas (Judt, 1996, p. 152). Hoy presenciamos la crisis de una Europa azotada profundamente por la Gran Recesión de 2007-2008. Sin una narrativa atractiva, sin un relato que ofrecer, Europa vivirá expuesta a las acusaciones de sus detractores. La asunción de un lema, un himno, una bandera o una moneda común fueron medidas encaminadas a afirmar un espacio de pertenencia europeo, pero ha sido, fundamentalmente, el imaginario que sirve de recordatorio de su experiencia fundacional. No obstante, si Europa quiere ser una comunidad imaginada efectiva, debe cuidar no sólo sus aspectos simbólicos, sino fundamentalmente su capacidad de mostrarse cercana y protectora de unos ciudadanos por el momento ausentes. Como ha sugerido C. Shore (2000, p. 226), la legitimidad popular de la que carece la Unión Europea no puede obtenerse únicamente mediante la apelación a un imaginario simbólico, sino que debe partir de una profunda operación de democratización de las instituciones comunitarias y una revisión de sus políticas económicas.

"Hace falta una Europa que proteja", declaró el recién electo presidente de la República francesa Emmanuel Macron en su primera entrevista concedida a medios internacionales en junio de 2017, palabras que insu- 
flaron esperanza en los medios europeístas. Sin embargo, la apuesta por esa Europa cercana a la ciudadanía se razonaba sobre el discurso analizado a lo largo de estas páginas. En palabras de Macron: "Pero deseo volver a retomar el hilo de la historia y recuperar la energía del pueblo europeo, para contener el auge de los extremismos y de la demagogia. Porque ésa es la lucha de la civilización". ${ }^{14}$ En una coyuntura de agotamiento de los relatos basados en la noción de progreso, revivir el mito europeo de la civilización puede ser un motivo de euforia o un discurso consolador para los círculos más eurófilos. El éxito o fracaso del reto presente depende de si la voluntad transformadora expresada en clave civilizacional se traduce en hechos concretos que permitan restablecer la cohesión social necesaria para construir el consenso entre instituciones y ciudadanía. Si no lo hace, el proyecto europeo corre el riesgo de quedar reducido a una estructura jurídica inmensa, una armazón institucional incomprensible, una enorme caja de resonancia de su propia retórica bienintencionada.

\section{Siglas y referencias}

BM, 1930: "A Union, Not a Unity. The Briand Memorandum". 1 de mayo de 1930. Documents on British Foreign Policy 1919-1939. $2^{\mathrm{a}}$ serie, vol. I, pp. 314-321. Recuperado de http://ucparis.fr/files/2513/4727/4778/ PCC115_Habibi_Briand_FA12.pdf

BT, 1948: The Brussels Treaty (17 de marzo de 1948). Recuperado de http://www.cvce.eu/obj/the_brussels_treaty_17_march_1948-en3467de5e-9802-4b65-8076-778bc7d164d3.html

CE, 1948: Congrès de l'Europe. Résolutions. Recuperado de http://www. cvce.eu/content/publication/2013/11/25/a7834206-8193-405b-be99 dffc600da240/publishable_fr.pdf

DEI, 1973: Declaration on European Identity (Copenhaguen, 14 de diciembre de 1973). Recuperado de http://www.cvce.eu/obj/ declaration_on_european_identity_copenhagen_14_december_1973en-02798dc9-9c69-4b7d-b2c9-f03a8db7da32.html

DS, 1950: Neuvième et dernier projet de la déclaration Schuman (6 de mayo de 1950). Recuperado de: http://www.cvce.eu/obj/neuvieme_et_dernier_projet_de_la_declaration_schuman_6_mai_1950-fr4909847d-df12-4c67-83d2-8e0978da025b.html

14 Entrevista a Emmanuel Macron publicada el 22 de junio de 2017 en ocho diarios europeos: Le Soir, The Guardian, Gazeta Wyborcza, Il Corriere della Sera, Le Temps, Süddeutsche Zeitung, Le Figaro y El País. Rescatado de: http://internacional.elpais. com/internacional/2017/06/21/actualidad/1498060288_982592.html 
SCE, 1949: Statute of the Council of Europe, London, 5.V.1949, No. 1. European Treaty Series. Recuperado de https://rm.coe.int/CoERMPublicCommonSearchServices/DisplayDCTMContent?document Id $=0900001680306052$

\section{Referencias bibliográficas}

Ahijado Quintillán, M. (2000)

Historia de la unidad europea. Desde los precedentes remotos a la ampliación al Este. Madrid: Pirámide.

Anderson, B. (1993)

Comunidades imaginadas. Reflexiones sobre el origen y la difusión del nacionalismo. México: Fondo de Cultura Económica.

Anderson, P. (2012)

El Nuevo Viejo Mundo. Madrid: Akal.

Bauman, Z. (2006)

Europa. Una aventura inacabada. Madrid: Losada.

Berger, S. (2005)

A return to the National Paradigm? National writing in Germany, Italy, France and Britain from 1945 to the present. The Journal of Modern History, 77, pp. 629-678.

Bitsch, M., W. Loth y R. Poidevin (1998)

Institutions européennes et identités européennes. Bruselas: Bruyllant. Brugmans, H. (1972)

La idea europea, 1920-1970. Madrid: Moneda y Crédito.

Cabrera, M., S. Juliá y P. Martín Aceña, comp. (1992)

Europa. 1945-1990. Madrid: Editorial Pablo Iglesias.

Cohen-Solal, A. (2005)

Jean-Paul Sartre. Barcelona: Anagrama.

Coudenhove-Kalergi, R. N. (2010)

Pan-Europa. Madrid: Encuentro.

Crespo MacLennan, J. (2009)

Forjadores de Europa. Grandes europeístas y euroescépticos del siglo $X X$. Barcelona: Destino.

Delanty, G. (1995)

Inventing Europe. Idea, Identity, Reality. Londres: Macmillan.

Dinan, D. (2004)

Europe recast. A history of European Integration. Hampshire: Palgrave Macmillan.

Eagleton, T. (2001)

La idea de cultura. Una mirada política sobre los conflictos culturales. Barcelona: Paidós. 
Folguera, P. (2009)

El debate en torno al modelo de construcción europea en Francia, Italia, Alemania y España (1930-1950) (1). Historia y política, 21, pp. 17-53.

Folguera, P. (2010)

Sociedad civil y acción colectiva en Europa: 1948-2008. Ayer. Revista de Historia Contemporánea. Europa desde 1945: El proceso de construcción europea, núm. 1, pp. 93-94.

Fontana, J. (1994)

Europa ante el espejo. Barcelona: Crítica.

Fontana, J. (2011)

Por el bien del imperio. Una historia del mundo desde 1945. Barcelona: Pasado y Presente.

Fusi, J. P. (2016)

La patria lejana. El nacionalismo en el siglo Xx. Madrid: Taurus.

García Picazo, P. (2008)

La idea de Europa: Historia, cultura, política. Madrid, Tecnos.

García Picazo, P. (2008)

Política e identidad cristiana en los padres fundadores de la Unión Europea. Cuadernos de Estudios Europeos, 1, (Robert Schuman. Instituto de Estudios Europeos, Universidad Francisco de Vitoria, Madrid).

Gellner, E. (2008) Naciones y nacionalismo. Madrid: Alianza.

Hall, S. (1991)

Europe's Other Self. Marxism Today, agosto, pp. 18-19.

Hobsbawm, E. (2001)

La era de la revolución. Barcelona: Crítica.

Judt, T. (1996) ¿Una gran ilusión? Un ensayo sobre Europa. Madrid: Taurus.

Judt, T. (2005)

Posguerra. Una historia de Europa desde 1945. Madrid: Taurus.

Judt, T. y T. Snyder (2012)

Pensar el siglo XX. Madrid: Taurus.

Juncker (2017)

La Unión Europea sufre una crisis existencial, pero no se va a romper. Euronews, 14 septiembre. Rescatado de http://es.euronews. com/2016/09/14/juncker-la-union-europea-sufre-una-crisis-existencial-pero-no-se-va-a-romper

Kundera, M. (1987)

El arte de la novela. Barcelona: Tusquets. 
Loth, W. (2008)

Explaining European Integration: the Contribution from Historians. Journal of European Integration History, vol. 14, 1, pp. 9-27.

Macron (2017)

Mi elección es el inicio de un renacimiento francés y espero que europeo. Entrevista al presidente de Francia. Marc Bassets. El País, 22 junio. Rescatado de: http://internacional.elpais.com/internacional/2017/06/21/actualidad/1498060288_982592.html

Mazower, M. (2001)

Europa negra. Desde la Gran Guerra hasta la caída del comunismo. Barcelona: Ediciones B.

Milward, A. S. (1992)

The European Rescue of the Nation State. Londres: Routledge.

Moreno Juste, A. (1999)

La idea de Europa: balance de un siglo. Cuadernos de Historia Contemporánea, 21, pp. 161-179.

Moreno Juste, A. (2013)

El fin del relato europeo. La crisis del proceso de integración y su impacto sobre las narrativas europeas. Revista de Derecho Comunitario Europeo, 45, pp. 607-630.

Morin, E. (2009)

Pensar Europa. Barcelona: Gedisa.

Ortega y Gasset, J. (1956)

La rebelión de las masas. Madrid: Austral.

Pagden, A. (2002)

The idea of Europe. From Antiquity to the European Union. Cambridge: Cambridge University Press.

Petrescu, C. (2011)

Concebir Europa desde el otro lado del Telón de Acero: intelectuales rumanos y centroeuropeos en comparación. Ayer. Revista de Historia Contemporánea. El socialismo de Estado: cultura y política, 82 (2), pp. 55-86.

Reverter Bañón, S. (2006)

Europa a través de sus ideas. Bilbao: Desclée de Brouwer.

Schuman, R. (2006)

Por Europa. Madrid: Encuentro.

Semprún, J. (2006)

Pensar Europa. Barcelona, Tusquets.

Shore, C. (2000)

Building Europe. The cultural politics of European integration. Londres: Routledge. 
Spengler, O. (1998)

La decadencia de Occidente. Bosquejo de una morfología de la historia universal. Tomo I. Madrid: Colección Austral, Espasa-Calpe.

Spinelli, A. y E. Rossi (2001)

Il Manifesto di Ventotene. Prefazione di Eugenio Colorni. Turín: Celid. Stern, F. (1974)

The Politics of Cultural Despair. A Study in the Rise of the Germanic Ideology. Berkeley: University of California Press.

Stråth, B. (2002)

A European Identity: To the Historical Limits of a Concept. European Journal of Social Theory, 5(4), pp. 387-401.

Traverso, E. (2009)

A sangre y fuego. De la guerra civil europea, 1914-1945. Buenos Aires: Prometeo Libros.

Thiesse, A-M (2010)

La creación de las identidades nacionales. Europa: siglos XVIII-XX. Madrid: Ézaro. 